\title{
Constitutional determinants of government spending ${ }^{1}$
}

\author{
Guido Tabellini \\ IGIER and Department of Economics, Bocconi University; \\ CEPR; CES-Ifo
}

February 2000

\footnotetext{
${ }^{1}$ This is a revised version of the first of my Munich Lectures in Economics, delivered at CES on November 16, 1999. I am greatly indebted to Torsten Persson, with whom I did all of the work summarized here, and who provided very helpful comments on this survey. I am also grateful to the participants in the lectures for their comments. Naturally, I am solely responsible for any errors or omissions.
} 


\begin{abstract}
This paper surveys some recent literature on fiscal policy and comparative politics. Economic policy is viewed as the outcome of a game with multipleprincipals and multiple-agents. Opportunistic politicians bargain over policy. Rational voters hold them accountable through retrospective voting. Political institutions determine the rules for legislative bargaining and for electing politicians to office. The questions asked are: how do alternative electoral rules and alternative regime types shape the size of government, the composition of spending, the performance of politicians in terms of effort or corruption, the features of electoral cycles. The paper discusses both theory and evidence, and concludes wiht some speculations about directions for future research.
\end{abstract}

Keywords: comparative politics, corruption, elections, fiscal policy.

JEL classifications: H0 


\section{Introduction}

How is fiscal policy chosen in representative democracies? And what determines the observed features of government spending and taxation? These are the general questions addressed in this paper. I will summarize recent joint research with Torsten Persson, of the University of Stockholm. Much of the theoretical work I will refer to is discussed at great length in our forthcoming book, Persson and Tabellini (2000). Some empirical results I will mention are described in detail in Persson and Tabellini (1999a) and in Persson, Tabellini and Trebbi (2000).

Motivation The motivation for asking these questions is easy to see. Looking across countries or across time, there are large variations in fiscal policies. In the late 1990's, total government spending as a fraction of GDP was more than $60 \%$ in Sweden, and well above $50 \%$ in many countries of continental Europe, but around 35\% in Japan, Switzerland, and the US. There are also striking variations in the composition of spending: transfers are high in Europe, but low in Latin America. Available measures of corruption vary a lot, even across countries with comparable levels of development and similar economic structure.

The Question How can we explain these variations in the data? And what are the sources of the common patterns? A large literature on public choice and political economics seeks to answer these questions, relating fiscal policy choices to a large number of political and economic determinants.

Here, I want to address a more specific question: what is the role of political institutions in shaping public spending? That is, I want to do an exercise in comparative politics, applied to fiscal policy. In particular, I will focus on two fundamental features of political institutions: (i) the electoral rule; (ii) the regime type, or more generally the procedures for approving and implementing legislation in presidential and parliamentary regimes.

There is a large literature on comparative politics, written by political scientists, that compares these two fundamental features of a political constitution. But typically, this literature is confined to the analysis of political phenomena: how the electoral rule affects the number of parties, or how the regime type affects the frequency of political crises, or protests by the citizens. There is also a small literature by economists, most notably on budgetary arrangements and federal institutions. But the work linking fiscal policy to fundamental constitutional features, such as the electoral rule and the regime type, was rather scarce until recently. 
My goal is twofold: to illustrate an analytical framework that can be used to address these questions; and to suggest some general lessons that are supported both by theory and evidence, concerning the effects of specific constitutional features on government spending.

Outline I will start by describing the main features of the analytical framework, first with regard to economics and then with regard to politics. Then I will turn to the electoral rule: I will contrast local vs national elections, as well as majoritarian vs proportional elections. The question here is how the electoral rule shapes the incentives of politicians to extract rents for themselves, and how it determines the composition of public spending. Next, I will discuss the regime type, contrasting parliamentary vs presidential democracies. Here the focus is on the size and composition of government spending. In addressing these questions, I will mention theoretical results as well as empirical evidence.

\section{The Analytical Framework}

Political institutions resolve conflicts. But the conflict we are interested in has an economic origin. Hence, I start with economics.

\subsection{Economics}

Throughout, I will refer to government spending financed out of the general budget, neglecting the issue of the timing and composition of tax revenue.

Who benefits It is useful to distinguish between three types of government spending, on the basis of how many people benefit from it. Government spending can provide benefits to:

(i) Many citizens.

(ii) Just a few citizens.

(iii) No one except the politicians.

Each of these types of policies induces a specific kind of economic conflict.

General public goods (like defense), or broad redistributive programs (like social insurance, or pensions), are examples of policies of type (i). Because of their broad nature and universalistic design, these programs cannot easily be tailored to the specific demands of well defined groups of citizens. Hence, they are evaluated in a similar fashion by large groups of beneficiaries. Many entitlement programs that are typical of the modern welfare state belong to this category. 
Local public goods or specific redistributive programs (like agricultural support, or transfers to government enterprises) are examples of policies of type (ii), that benefit only a few citizens. This kind of spending is referred to as "pork barrel", and often, though not always, reflects discretionary policy decisions.

The third type of government spending are rents for politicians. Rents can take various forms, depending on specific economic circumstances: literally, they are salaries for public officials or financing of political parties. Less literally, one can think of various forms of corruption and waste as ultimately providing rents for politicians.

While broadly or narrowly targeted programs induce conflict among voters, rents for politicians are at the core of the agency problem pitting voters at large against politicians. The resources appropriated through rents are probably small in most modern democracies, compared to the overall size of tax revenues. But since these "crumbs" directly benefit the agents in charge of policy decisions, they can nevertheless induce a strong influence on other policy decisions.

The question I will address is: what determines the size of these types of spending, both when considered in isolation and when jointly determined?

\subsection{Politics}

If the policy instrument determines the kind of economic conflict, the political institution determines how this conflict is resolved. To this I turn next.

Lack of microfoundations A feature of the modern literature in political economics is that there is not a single accepted analytical model of the political process. The current state of the art in political economics resembles that of macroeconomics in the mid 1970s: there is no consensus on the necessary ingredients of a successful theory.

I think this is so because there has been an inadequate effort to study and formalize the process of policy formation as a well specified game played by rational players. Politics is often modeled as a black box, with insufficient analysis of who decides what, under what incentives, or with what information. In a few words: political economics still lacks micro-political foundations.

Four principles In our recent joint work with Torsten Persson, we have proposed four principles or assumptions that can provide the building blocks for such microfoundations. 
(i) Delegation: As stated in the title of this paper, policy is chosen by elected representatives, not directly by the citizens.

(ii) Campaign promises are not binding: policy is chosen by politicians once they are in office, not before the elections.

(iii) Opportunistic politicians: incumbent politicians want to remain in office, and care about the rents they receive. They choose policy so as to further these goals, but otherwise do not care about what policy is implemented.

(iv) Retrospective voting: voters control politicians at the elections, by looking back at past policy performance. If they are pleased with the behavior of their representative, they reward him with reappointment. Otherwise they throw him out of office.

Delegation games Overall, these four principles are simple, though logically consistent and complete. They can provide the micro-political foundations for a positive theory of policy choice. Observed policies can be viewed as the equilibrium outcome of a delegation game. At the core of this delegation game there is a fundamental agency problem between voters and elected politicians. But as the voters also disagree among themselves, it is a common agency problem, with conflict among the principals as well as between the principals and their elected representative.

The role of elections These microfoundations also suggest a specific role for elections: as in the "liberal" tradition, elections allow the voters to remove from office a bad incubment (or one who mis-behaved). This role of elections is very different from the "populist" view, that elections enable the voters to select the appropriate policy.

Comparative politics Finally, this appoach to politics as a delegation game forces the theorist to be precise about two fundamental aspects of the rules of the game: (i) the electoral rule, and (ii) the procedures governing policy choice by the elected incumbents. It is then natural to ask what are the effects of changing these rules of the game. That is, comparative politics is a natural, almost inevitable, item in this research program.

This is precisely what I will do in the remainder of this survey: I will contrast alternative rules of the game, namely alternative rules for electing politicians in office, and alternative procedures for approving and implementing legislation once in office.

To keep the analysis simple, I will address these two questions separately. Thus, when analyzing the effects of the electoral rule, I will make the sim- 
plifying assumption that there is a single politician in office who sets policy. And when contrasting alternative legislative procedures governing collective choice by several politicians who share office, I will keep the electoral rule fixed and corresponding to plurality rule in single-member district. This simplification is clearly just a starting point, which ought to be relaxed by future research.

\section{Elections and Rents}

I start with the electoral rule.

Consider first a very simple example, with no conflict among the voters. There is only an agency problem, namely a conflict between the incumbent politician and the voters at large. All voters unanimously agree: they would like rents to be as small as possible, while the incumbent wants the opposite.

\subsection{Local vs National Elections}

I want to contrast local vs national elections. More generally, the question I want to address is:

Does decentralization lead to more or less rents? Consider a situation in which policy consists of a multitude of tasks. Each task affects the welfare of voters in a specific locality. These tasks can be thought of as the provision of a local public good paid out of local tax revenues; or the regulation of a local public utility; or the provision of any local service, whose costs and benefits only accrue to the residents of that locality. For simplicity assume that there are no spillovers across localities.

Performance in these tasks depends on two things only: chance and effort. Effort is costly for the incumbent (or equivalently, if cash is involved, effort means abstaining from grabbing rents). To simplify, assume that the disutility from effort for the incumbent is additive. That is, the marginal cost of putting effort into one task does not depend on how many tasks the agent is performing (or equivalently, if we interpret rents as cash, his marginal utility of income is constant)

There are two possible institutional arrangements.

(i) Decentralization. That is, each task is performed by a different politician, separately accountable for his performance to a specific locality through local elections.

(ii) Centralization. There is a single politician performing a multitude of tasks and jointly accountable to a number of localities. 
The question is: which arrangement is better from the voters' point of view? In answering it, I will draw on theoretical work by Seabright (1996) and Persson and Tabellini (2000), and empirical work by Fisman and Gatti (1999).

Theory Note that, in the formulation of this problem, we abstract from the typical complications of multi-tasking (since there are no externalities for the voters and no economies or dieconomies of scale in performing a multitude of tasks). Thus, in a standard principal-agent problem, with no constraints on the compensation scheme offered to the agent, the principals would be indifferent between these two arrangements.

But the voters are not indifferent. The reason is that, in a political context, the principals are constrained to offer only an implicit reward, namely re-appointment for good performance.

Under decentralization, good performance in a specific task is directly rewarded with reappointment. Thus, politicians can be held directly and separately accountable for what they do.

Under centralization, on the other hand, the accountability mechanism is more indirect. A politician is rewarded with reappointment only if his aggregate performance is satisfactory (or more precisely, only if he pleases at least half the localities). This weakens the incentives to perform well, since there is a smaller link between effort and rewards.

This does not mean that decentralization is always preferable, however. As a national office is more prestigious and powerful, the incumbent cares more about reappointment. Hence, despite the more indirect link between effort and rewards, it could very well be that equilibrium effort is greater under centralization. A priori, the result is ambiguous: decentralization can be bad or good for the voters, depending on whether the more direct accountability is or is not offset by the smaller value of reappointment.

The evidence What do the data suggest about this important question ? It is difficult to answer, because rents are hard to measure. But suppose that we are willing to assume that political rents are higher where there is more corruption. Then, we can use available cross country surveys on corruption and estimate their correlation with observable measures of fiscal centralization. What do we find ?

The answer, suggested by the empirical work of Fisman and Gatti (1999), and confirmed by regressions I have performed in a smaller sample of countries, is clear: more decentralization is associated with much less corruption. Overall, therefore, it appears that decentralization is good for the voters. 


\subsection{Majoritarian vs Proportional elections}

The conceptual distinction between local vs national elections is related to another important and often discussed distinction, between majoritarian and proportional elections.

Electoral rules differ along many dimensions, and the classification between Proportional and Majoritarian systems hinges on more than one aspect. The traditional view in political science is that the two most important aspects of this classification are district magnitude (i.e., the number of seats in a district), and the electoral formula (i.e., how votes are translated into seats).

Majoritarian elections have small district magnitude (typically one candidate is elected in each district), and the electoral formula is plurality rule (the winner is the candidate who gets more votes in the district). At the opposite extreme, proportional systems have large districts with many candidates (the Netherlands has just a single district where all 150 representatives are elected), and voters vote for a list of candidates drawn up by political parties, without expressing a preference for any particular candidate; the number of candidates elected in each list is proportional to the votes received by the list. But in between these two polar extremes there are many variations and intermediate cases.

The question I want to ask is similar to the previous one: Which electoral system leads to smaller rents?

The answer may differ depending on which feature of the electoral rule is considered.

Barriers to entry Consider first district magnitude. It is commonly accepted among political scientists that small districts increase the barriers to entry (see for instance Myerson (1993), Ferejohn (1986)). New candidates are less known and may find it difficult to reach a relative majority. Hence, if only one candidate is elected in each district, it is more likely to be the incumbent or some old politician already well known in the constituency. Large districts that appoint several candidates, on the other hand, are more likely to get down to new and less known candidates that only appeal to a minority of the voters. Thus, proportional systems with large district magnitude tend to have smaller barriers to entry. And it is plausible to guess that small barriers to entry, and hence stiffer competition and more contendibility, are associated with smaller incumbency rents.

Electoral formula But if we consider the electoral formula (how votes translate into seats), we are led to a different conclusion. The reason is 
similar to that already discussed with regard to local vs national elections.

When voters vote for an individual candidate, there is a direct link between individual performance and individual reappointment. Hence, the incumbent faces strong incentives to perform well, putting in effort or avoiding corruption. When instead voters vote for a list, candidates face much weaker incentives. Their chances of re-election depend on their rank in the list, not on their performance. And if the party leader draws up the list on the basis of criteria unrelated to performance (for instance, party loyalty, or effort within the party rather than in office), then the incentives to perform well are much weaker.

Thus, here we are lead to the conclusion that majoritarian systems with plurality rule lead to smaller rents and less corruption, compared to proportional systems where voters vote for a list - this result is derived in Persson and Tabellini (2000).

Again, thereofore, a theoretical comparision of majoritarian vs proportional systems leads to overall ambiguous results. Majoritarian systems tend to have higher barriers to entry but also more direct accountability to the voters than proportional system. The net effect is ambiguous, depending on which of these two fetaures is quantitatively more important.

The evidence What does the evidence say on this?

The answer, suggested by the empirical work of Persson, Tabellini and Trebbi (2000), is that direct accountability seems to be the dominant factor. In a large sample of countries, those where voters vote for a party list have much more widespread corruption compared to countries where voters choose an individual candidate. Overall, majoritarian elections seem to be associated with less corruption.

This confirms a view prevalent in Italy, where recent electoral reform in favor of a more majoritarian system was forced by the citizens through a referendum, as a way to end the corrupt habits of the past.

\subsection{Summary}

Summarizing, I have emphasized a key feature of a political system: the extent to which good performance is rewarded by the voters with reappointment. Different electoral rules and different regime types differ in this crucial respect, and this in turn leads to some comparative politics results and to specific positive predictions.

Local elections and majoritarian systems provide a more direct link between individual performance and re-appointment, and thus the incentives to 
reduce rents are stronger, compared to centralized and proportional elections. This is confirmed by the evidence from cross-country data.

\section{Electoral Cycles}

These institutional comparisons all stem from a common idea: satisfactory performance is rewarded with reappointment. This idea in turn leads to the positive prediction that performance is better just ahead of elections. That is, there is an electoral cycle: as the election date approaches, the incentives to perform well become stronger. Pushed to the limit, this idea has a seemingly paradoxical implication: that elections ought to be held very frequently, so as to always give incumbents very strong incentives to perform well.

But strong incentives to perform well are not necessarily helpful for the voters. The reason is that voters may be mis-informed (though still rational). To put it another way: reappointment is related to the appearance of good performance. But not always what appears good is really so. And if the voters are not well informed, then electoral incentives may induce the incumbent to introduce policy distortions for the only purpose of improving perceived (but not actual) performance.

I offer three examples.

Output and inflation In macroeconomics it is commonly accepted that inflation lags real output. There is also ample evidence that voters reward good performance as summarised by aggregate real economic growth. Combining these two stylized facts, we are quickly led to the conclusion that an incumbent politician has an incentive to boost aggregate demand jsut ahead of the elections. If he succeeds with the right timing, and if voters are not fully informed, output growth accelerates just ahead of the election and the inflationary consequences only appear to the voters when it is too late. Under rational expectations, everyone including economic agents expect this to happend, and thus there need not be any real output effect. But the incentive to manipulate aggregate demand remains, and we are led to the prediction that inflation accelerates just after the elections, while aggregate demand is boosted through expansionary policies just ahead of the elections. Alesina and Roubini (1998) provide evidence that this electoral cycle is indeed observed in many industrial countries.

Exchange rates A related implication concerns exchange rate policies. Expansionary aggregate demand policies leading to inflation are also likely 
to eventually induce a nominal depreciation of the exchange rate. But depreciation is unlikely to be rewarded by the voters; on the contrary, a devalued exchange rate is often regarded by public opionion as a symptom of macroeconomic mis-management. Opportunistic governments therefore have strong incentives to postpone devaluations until after the election. This incentive may be strenghtened by the observation that an appreciated real exchange rate often boosts the purchasing power of consumers who can afford to buy ceaper imported goods, thus creating an artificial sense of affluence and well being. But if the exchange rate is out of equilibrium, this cannot last. Once the election is over, the incentives to defend the exchange rate are gone, and a devaluation takes place. Once more, the data seem supportive of the idea that there is an electoral cycle in exchange rates.

Public spending Similar observations apply to government spending. Often it is possible to increase government spending just ahead of the elections, while postponing the moment when taxes are raised to pay for it, or spending cuts may be needed. There are several ways of doing that: through manipulation of the timing of cash outflows, or by incurring debts with the banking system rather than in the more visible market place, through other off budget items. Whatever the technical device chosen, this electoral cycle in government spending creates the appearance of good performance in the eyes of the voters, while hiding the true costs of the operation. Again, there is scattered evidence of this kind of electoral spending cycle within individual countries.

Electoral rules What does this have to do with comparative politics?

It could have much to do. According to the previous arguments, different features of the electoral system affect the incentives to perform well (or, equivalently, to appear to perform well). Where these incentives are stronger, the electoral cycle is more pronounced, whatever form it takes.

Thus, if indeed local elections provide stronger incentives to perform well, as suggested by the empirical evidence on corruption, we should also observe more pronounced cycles in government spending at the local as opposed to national level.

And if indeed majoritarian systems provide stronger individual incentives for good performance, then the electoral cycle in inflation, or exchange rates, or budget deficits, ought to be more pronounced in majoritarian systems than under proportional representation. 


\section{$5 \quad$ Elections and the Composition of Spending}

So far I neglected the common agency aspect of politics: all voters were assumed unanimous in their policy evaluation. I now discuss another effect of the electoral rule, that becomes important when voters disagree on the allocation of spending. Here I will draw on some recent results by Persson and Tabellini (1999).

The policy For simplicity I abstract from rents, at least for a while. The policy decision is a cake splitting type of problem. A budget of a given size must be allocated between a general program that benefits a large number of voters (for instance, or a broad and universalistic type of program), and several narrowly targeted programs (such as local public goods or agricultural support), each benefiting a small group of beneficiaries.

The voters Suppose that all voters adopt a retrospective voting rule: they vote for the incumbent party if they have reached a sufficiently high level of welfare. Otherwise, they vote for the opponent.

Suppose also that different voters differ in their reservation utilities. Some voters are very hard to please and seldom vote for the incumbent no matter what. Others are much less demanding. The incumbent party ignores the exact reservation utility of individual voters, though it knows the distribution from which they are drawn.

The question How does the electoral rule influence this policy decision? As before, elections reward the incumbent for his performance, and the electoral rule determines how direct is the link between performance and reward. But now, performance is related to the redistributive struggle among voters, not to abstaining from grabbing rents. Is it still a good idea to have sharp electoral incentives in this case?

The electoral rule Specifically, I will contrast two extremes: A purely proportional system with a single national district that elects the whole legislature. And a majoritarian system, where each seat is assigned to a specific district under plurality rule.

To keep things simple, I neglect the difficult question of how to deal with coalition governments (or equivalently, with many politicians who share office). I will return to this question later. Thus, I assume a two party system. A single party with an absolute majority is in office, and is faced by a single opponent. 
Under both electoral systems, the incumbent party wins and is reappointed in office if he gets at least $50 \%$ of the seats. But under proportional elections, this event is equivalent to winning at least half the votes in the single district (i.e., half the votes in the population). Under majoritarian elections, instead, victory is obtained if the incumbent party wins at least half the votes in half the districts (i.e., $25 \%$ of the votes in the population).

That is, proportional elections lead the incumbent to go after votes. While majoritarian elections lead him to go after districts. Clearly, these two systems provide the incumbent with different incentives.

The incumbent policy choice To see why, consider the choice faced by the incumbent. He has to choose between two alternative strategies, that is between an intensive or an extensive margin.

Either he seeks to please just a few voters by a lot. In this case he is very likely to win the vote of the voters he targets, but he has a small extensive margin: if just a small fraction of voters does not reward him with a vote, he can loose the election.

The alternative strategy is to go after the extensive margin. Namely, to seek to please a large number of voters by just a little. In this case, each voter has a non-negligible probability of not voting for him, but since there are many voters in that situation and each voter acts independently, this may still be a risk worth taking.

Narrowly targeted redistribution is the policy tool with which to pursue the first (intensive) strategy. General public goods and broad and universalistic redistribution is the appropriate tool to pursue the second (extensive), strategy.

The key point is that the electoral rule determines which of these two strategies is best.

District magnitude With proportional elections and a single national district, the incumbent party needs to please a large number of voters to insure victory. Hence, the extensive margin is more important: he has a strong incentive to provide broad benefits to many voters, through public goods or broad redystributive programs.

With majoritarian elections and many single member districts, on the other hand, the intensive margin is more important. The incumbent now faces strong incentives to direct benefits to a few key marginal districts, neglecting the districts where he is either a sure winner or a sure loser.

Thus, we have a positive prediction: majoritarian elections with single member districts lead to more narrowly targeted redistribution. While pro- 
portional systems with large district magnitude lead to broader redistributive programs and more provision of general public goods.

Voting for a list or for a candidate As noted above, majoritarian and proportional elections also differ in the electoral formula translating votes into seats. This institutional dimension too is relevant for the allocation of government spending, and reinforces the effect of district magnitude.

When voters choose a list, rather than a single candidate, political parties are more powerful. Hence the policy that is implemented is likely to reflect what is optimal for the party, as opposed to the individual candidate. This typically reflects a national perspective, and hence is more likely to favor broad forms of redistribution.

When voters select a candidate, on the other hand, political parties become less powerful. Government policy is more likely to reflect the perspective of individual members of the legislature. They in turn are more interested in their own district, and less interested in what happens throughout the nation. Hence, particularistic redistribution is more likely.

Evidence Summarizing, then, the electoral rule shapes the incentives to choose the mix of spending. Majoritarian elections have smaller districts and voters select individual candidates. Both features lead the government to spend in the form of narrowly designed redistributive programs that benefit small constituencies.

Proportional electoral systems, on the other hand, have large districts and the vote is cast for a party list. Here, government spending is more likely to take the form of broad redistributive programs and general public goods that benefit a large number of voters.

Is the evidence consistent with these predictions?

Clearly, there is a gap here between the theory and the data. But suppose that we are willing to identify the programs that have broad redistributive objectives with social security and welfare spending. Then, cross country comparisons confirm the theoretical predictions: social security and welfare spending is larger in proportional systems than in countries ruled by majoritarian elections. Again, this finding is very robust, and it holds both when we measure spending as a fraction of GDP or of total government spending. Milesi-Ferretti, Perotti and Rostagno (1999) have obtained it in a sample of OECD countries, but it holds also in a much broader sample of heterogeneous countries.

Similar results have been obtained by Persson and Tabellini (1999) for some categories of spending that we could classify as provisions of public 
goods, such as order and safety, or public education.

\section{Regime Types}

So far I have assumed that a single incumbent politician is in charge of policy making. When we relax this assumption, our attention is immediately directed to the institutions that govern collective decisions by elected politicians: the budgetary and legislative procedures, the rules for government formation and dissolution, the ways in which nominations to powerful commitees or agencies are made, and so on. A whole new dimension of comparative politics opens up.

Not much has been written by economists (or with the tools of economists) on these issues, however. This area remains largely unexplored, at least if we confine ourseleves to the formal analytical literature.

\subsection{Presidential vs Parliamentary Regimes}

Here I will focus on a fundamental constitutional distinction: between presidential and parliamentary democracies. I will extensively draw on recent work by Persson, Roland and Tabellini (1997), (1998), summarized also in Persson and Tabellini (1999), (2000).

The power to propose There are many ways to contrast parliamentary and presidential regimes. A particularly useful one has to do with the way they regulate the power to set the agenda.

Political scientists have long emphasized the importance of agenda setting power. The stronger is this power, the more the individual who holds it can influence the collective decision. All political constitutions regulate the excercise of this power, diluting it in different ways and imposing various checks and balances. But parliamentary and presidential democracies regulate agenda setting power in very different ways.

Parliamentary vs presidential regimes The key question is who has such agenda setting powers?

In a parliamentary democracy, the power of setting the political agenda rests with the government: it is the government who initiates legislation, who drafts the budget, who has priority in proposing major reforms.

In a presidential democracy such as the US, instead, the agenda setting powers of the President are much smaller. The president has a veto right, it has important agenda setting powers in foreign policy, in defense and even 
in international trade policy. But in the realm of domestic economic policy, the power to propose mainly rests with Congressional committees.

This observation suggests that parliamentary and presidential democracies differ along two dimensions:

Allocation (i) how agenda setting rights are allocated among different individuals or offices: in a parliamentary democracy they are shared within government; in a presidential democracy, they are dispersed among different offices (i.e., different Congressional committees).

Maintainance (ii) how agenda setting rights are preserved over time: in a parliamentary democracy, a government maintains its agenda setting power only for as long as it enjoys the support of the majority in the legislative assembly; in a presidential democacy, on the other hand, the holders of these powers (the Congressional committees) typically retain these powers throughout the legislature.

Checks and balances Thus, presidential and parliamentary regimes impose checks and balances on elected officials in very different ways.

In a parliamentary regime, a coalition of representatives (the government) is invested with very strong and comprehensive powers of initiative. But they are subject to the constant threat of losing these powers if Parliamentary support breaks down.

In a presidential regime, on the other hand, no single office is invested with very comprehensive powers of initiative: different comittees are powerful in different and much more limited policy dimensions. But these powers are assigned once and for all throughout the legislature.

The question What are the implications of these institutional differences for economic policy? Like with the electoral rule, it is useful to distinguish between two different policy issues: the size of rents for politicians, and the composition of spending in terms of broad vs narrow redistribution (or general vs local public goods).

\subsection{Regime Type and Rents}

I start with rents. Thus, suppose again that voters are unanimous in their evaluation of policy. There is only an agency problem: all voters want rents as small as possible, while incumbent politicians want the opposite. 
But now, in contrast to what we discussed before, there are many agents, not just one. Hence, there is an additional policy dimension: how to allocate rents among different incumbent politicians. This creates conflict between incumbent politicians who fight for appropriating these rents.

Parliamentary regime In a parliamentary regime, this additional dimension of political conflict among politicians does not play an important role. Since government has to behave as a unitary player, ultimately it faces the same incentives as a single politician. Voters hold politicians accountable through elections. Thus, the majority coalition in parliament trades off rents vs votes, knowing that grabbing more rents reduces the chances of re-election.

Presidential regime In a presidential regime, on the other hand, political conflict among different incumbent politicians can play a much bigger role. Agenda setting powers are separated, not shared. Moreover, each politician is directly accountable to the voters. Outright disagreement among politicians or changes in the voting coalitions do not lead to a government crisis. Hence, there are fewer incentives to collude and more opportunities for open disagreement.

The key point is that, under appropriate checks and balances, this conflict can be exploited by the voters to induce politicians to discipline each other.

An example Consider a concrete example. Suppose that there are two politicians or committees. One exerts strong influence over how rents are split among politicians. The other determines the overall size of aggregate rents.

Conflict between these two politicians plays into the hands of the voters. Unless collusion is possible, the politician in charge of the allocation is a residual claimant of any additional aggregate rents. But this then reduces the interest of the other politician in keeping overall rents large. This other politician realizes that he does not benefit much from larger aggregate rents. If he can do something to reduce overall rents and increase his chances of re-election, he will do it.

There are many ways in which this can happen in practice: by revealing more information to the voters, by limiting the size of the budget, by putting more effort to the benefit of the voters.

Summary The general insight, then, is that a presidential regime has a deeper separation of powers and more direct accountability to the voters, compared to a parliamentary regime. A presidential regime invites conflict 
and competition among politicians. A parliamentary regime instead invites collusion among them. Hence, overall rents to politicians are likely to be larger in a parliamentary regime.

\subsection{Regime Types and the Composition of Spending}

It is tempting to conclude that the voters are better off under presidential as opposed to parliamentary regimes. But such a normative conclusion would be too rushed.

The reason is that a presidential regime also exacerbates conflict among voters, not only among politicians. And since the voters are the principals, conflict among them can lead to other inefficiencies.

To see this more clearly, let's add another policy dimension, so that public policy can also redistribute among voters. Specifically, spending can be put to the following alternative uses:

(i) rents for politicians;

(i) general programs that benefit a large number of voters (like general public goods or broad redistributive programs);

(iii) narrowly targeted programs each benefiting a small group of beneficiaries (like local public goods or minoritarian redistribution).

The question is: how does the regime type influence the composition of government spending?

Parliamentary regime In a parliamentary democracy, policy is set by the government - that is by representatives of a majoritarian coalition in Parliament. Hence, whatever the bargaining method inside the coalition, policy is likely to be jointly optimal for the coalition members.

This means that the government will seek to please a majority of voters (namely the constituency of the majoritarian coalition in parliament). Since there are many voters to please, this goal is efficiently pursued by allocating government spending to broad redistributive programs and general public goods, that benefit a large number of voters.

Presidential regime In a presidential regime, on the other hand, different Congressmen are responsible for different aspects of policy. Moreover, each Congressman is accountable to a different constituency of voters.

To please his constituency, therefore, each Congressman will try to direct resources towards his electoral district and away from other districts. Narrowly targeted redistribution is the most efficient policy instrument to achieve this goal. Broad redistributive programs and general public goods 
are a waste, as they provide benefits to many more voters than each single politician cares about.

Thus, the sharper conflict amomg politicians also induces a sharper conflict among voters. The end result is that in a presidential regime redistribution takes the form of narrowly targeted and selective programs or local public goods, while general public goods and broad redsitributive programs are smaller.

Electoral rules and regime types There is an analogy here with what we already discussed when comparing electoral rules - or perhaps more than just an analogy.

Parliamentary regimes and proportional elections induce politicians to seek the support of a large number of voters. Hence, they lead to broader redistributive programs and more provision of general public goods.

Presidential regimes and majoritarian elections, on the other hand, induce politicians to seek the support of pivotal but minoritarian groups of voters. Hence, they lead to more narrowly targeted redistribution and a smaller quantity of general public goods.

\subsection{Regime Type and the Size of Government}

What does all this imply for the overall size of government?

So far we argued that presidential regimes are likely to have:

(i) small rents for politicians; and

(ii) redistribution towards powerful political minorities.

Both features are likely to imply a small size of total government spending. When we look across countries or time, the large spending items are typically the broad redistributive programs of the modern welfare state (public pensions, health, social insurance). These are precisely the programs that presidential regimes are less likely to inflate.

There is a further argument supporting the conclusion that the size of government is smaller in presidential regimes. Minoritarian redistribution and local (as opposed to general) public good provision implies that many voters are unlikely to benefit from government spending. A majority of the voters is thus likely to favor a small government and low taxation, because at the margin they are not residual claimants of additional tax revenues.

With sufficient separation of powers inside Congress, the wish of this majority is likely to be reflected in actual policy decisions. The reason is that, with adequate separation of powers, the key politicians who can exert strong influence over the size of the budegt are not also influential in determining 
how the budget is allocated. Hence, the interest of these politicians will be aligned with those of their voters who want low taxation.

Summarizing, the prediction of the theory (formulated more precisely by Persson, Roland and Tabellini (1998)), is that presidential democracies have smaller governments, less rents, less public goods and more narrowly targeted redistribution, compared to parliamentary regimes.

\subsection{The Evidence}

Is this prediction consistent with the empirical evidence?

With regard to the growth in the size of government, the answer is a clear and resounding yes. After controlling for many other political and economic determinants of government spending, Persson and Tabellini (1999) show that presidential democracies spend a lot less than parliamentary regimes (about $10 \%$ of GDP less).

The other theoretical predictions, concerning rents and the composition of spending, are not immediately supported by the data, but they remain to be investigated in greater detail.

\section{Concluding remarks}

I have built on a simple idea. A political constitution is like an incomplete contract. Policy is set by politicians once they are in office. These politicians seek reappointment and wish to grab some rents for themselves. And voters reward good performance with re-election. Electoral rules determine how direct is the link between policy performance and electoral reward. The regime type lays out the rules for bargaining and decision making by politicians once they are in office. These two institutions thus shape policy choices in a predictable way.

Some of these predictions are strongly supported by cross country comparisons.

Corruption is less widespread where citizens cast their vote for a candidate rather than for a party list.

Redistribution is directed towards larger groups of beneficiaries under proportional electoral systems with large district magnitude than in countries with single-member districts.

Presidential systems have smaller governments. 
Directions for future research But what I have illustrated is only the tip of the iceberg. The bulk of this economic approach to comparative politics is yet to be developed. As discussed at greater length in Persson and Tabellini (2000), much more work remains to be done, both linking the theory and the evidence, and developing other theoretical predictions.

Here are a few examples of what the most interesting open problems.

1. Alternative constitutional rules When discussing alternative electoral rules, it was assumed that policy was set by a single incumbent. Conversely, when discussing alternative regime types, I maintained the assumption of a majoritarian election with each politician elected in a separate single-member district.

How can these assumptions be relaxed? In particular, with reference to parliamentary democracies, what is the effect of alternative electoral rules on legislative bargaining inside the legislature or inside government? And what is the effect of alternative rules for government formation and dissolution? How do they interact with the electoral rule? Very little is known about these fundamental questions.

2. Voters' behavior Throught, I maintained the assumption that voters vote retrospectively. Although consistent with much empirical evidence, this assumption raises a number of questions.

How exactly do voters behave? How rational and informed are they? How strategic? What is the role of ideology in determining how they vote? Different answers to these questions could provide the ingredients of alternative political theories, while maintaining the same common microfoundations.

3. Motivation of politicians Throughout, I also maintained the assumption of opportunistic politicians who only care about winning the elections or grabbing rents. This cynical point of view can be defended on methodological grounds.

But individual political behavior - by voters as well as politicians - sometimes is driven by "ideological" considerations that transcend individual benefits, by a sense of what is just or legitimate, or by a particular view about the consequences of economic policy or the role of the state. Political opportunism assumes all of this away, and it is thus unable to explain why different politicians sometimes enact very different policies, or why they take seemingly unpopular policy decisions.

How can ideological political behavior be added to these theories of comparative politics? And more generally, how can we study ideology with the 
tools of economists? How far can we push the analogy between ideology and a brand name that preserves the voters' loyalty to political parties?

End Similar questions could be asked about the role of political parties as opposed to individual candidates, other forms of political participation besides voting, such as lobbying or protests, and naturally other economic policies, besides fiscal policy

I could go on and on. It is hard to find a research agenda in economics where the issues are so important, the gap between what we know and what we would like to know is so large, and yet where rapid progress seems within reach.

It's no exaggeration: I am really convinced that this is just the most exciting area of current research in economics. If I have convinced some readers that this is so, and that it is worth thinking hard about these questions of comparative politics with the standard tools of economists, then my main message has gone through. 


\section{References}

\section{References}

[1] Alesina, A., Roubini, N, and Cohen, G. 1997. Political Cycles and the Macroeconomy. Cambridge: MIT Press.

[2] Ferejohn, J. 1986. "Incumbent performance and electoral control." Public Choice 50: 5-26.

[3] Fisman, R. and R. Gatti 1999. "Decentralization and corruption: crosscountry and cross-states evidence", mimeo, World Bank

[4] Milesi-Ferretti, G.-M., Perotti, R., and Rostagno, M. 1999. "Electoral systems and the composition of public spending." Mimeo. Columbia University.

[5] Myerson, R. 1993a. "Effectiveness of electoral systems for reducing government corruption: A game theoretic analysis." Games and Economic Behavior 5: 118-132.

[6] Persson, T., Roland G., and Tabellini, G. 1997. "Separation of powers and political accountability." Quarterly Journal of Economics 112: $1163-1202$.

[7] Persson, T., Roland, G., and Tabellini, G. 1998. "Comparative politics and public finance", forthcoming in Journal of Policical Economy.

[8] Persson, T. and Tabellini, G. 1999a. "The size and scope of government: Comparative politics with rational politicians, 1998 Marshall Lecture." European Economic Review 43: 699-735.

[9] Persson, T., Tabellini, G., 1999b. "Political economics and public finance." Forthcoming in A. Auerbach, Feldstein, M., eds., Handbook of Public Economics. North Holland.

[10] Persson, T. and Tabellini, G. 2000. "Political Economics - Explaining Economic Policy" MIT Press, forthcoming

[11] Persson, T., G. Tabellini and F: Trebbi 2000. "Do proportional elections corrupt?", work in progress, Bocconi University

[12] Seabright, P. 1996. "Accountability and decentralization in government: An incomplete contracts model." European Economic Review 40: 61-89. 